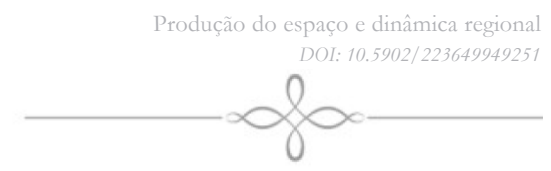

\title{
A aplicação do conceito de região no Plano de Desenvolvimento Sustentável da Região Turística (PDSRT) do Meio-norte (Brasil)
}

Luana Lima Bandeira Araújo*

Resumo: O conceito de região acaba sendo empregado largamente sem ter seu devido tratamento epistemológico. No Plano de Desenvolvimento Sustentável da Região Turística (PDSRT) do Meio-Norte, este fato não é diferente. Considerado como uma recente política pública de turismo no Brasil (2009), o PDSRT do Meio-Norte ou Plano Meio-Norte foi desenvolvido na região do Nordeste brasileiro, em especial nos estados do Ceará, Piauí e Maranhão. Dessa forma, a proximidade histórica que este conceito possui com o vetor político demonstra um conjunto de complexidades regionais passando a sobrepujar o arcabouço teórico de sua base conceitual. Assim, observa-se que não é a existência ou não da região, mas o campo dos usos desse conceito como justificativa de delimitações espaciais para fins determinados.

\section{The application of the concept of region in the Plan for Sustainable Develop- ment of the Tourism Region (PDSRT) of the Mid-north (Brasil)}

\footnotetext{
Abstract: The concept of region ends up being used widely without having its proper epistemological treatment and in the Plan for Sustainable Development of Touristic Region (PDSRT) of the Mid-North Sub Region of Brazil this fact is no different. The PDSRT Mid-North or Mid-North Plan was developed in the Northeast region of Brazil, especially in the states of Ceará, Piauí and Maranhão, and is considered as a recent public tourism policy in Brazil (2009). That way, the historical closeness that the concept of Region has to the political sector in Brazil shows regional complexities going to overcome the theoretical framework of its conceptual basis. Thus, it is observed that is not the existence or not of the Region, but the field uses this concept as a justification of spatial boundaries for certain purposes.
}

* Mestre em Geografia pela Universidade Federal do Ceará (UFC). Doutoranda pelo Programa de Pós-Graduação em Geografia na mesma universidade.

\section{Palavras-chave:}

Região; turismo; políticas públicas de turismo.

\section{Key-Words:}

Region, tourism, public tourism policies 


\section{Introdução}

A Política Nacional de Desenvolvimento Regional (PNDR) foi Institucionalizada através do Decreto $\mathrm{n}^{\circ} 6.047$ de 22 de Fevereiro de 2007 (Brasil, 2007), tendo como principal objetivo: reduzir as desigualdades regionais e ativar as potencialidades das regiões no País. Esta política engloba todo o território nacional e é centralizada pelo Governo Federal por intermédio do Ministério da Integração Nacional.

${ }^{2} \mathrm{O}$ Ministério da Integração Nacional, aprovado pelo Decreto $\mathrm{n}^{\circ} 5.847$, de 14 de julho 2006 é um órgão do Governo Federal tendo como principal desafio integrar as políticas públicas setoriais numa escala regional.

Geografia Ensino \& Pesquisa, v. 18, n. 2 p. $25-38$, maio/ago. 2014

A aplicação do conceito de região no Plano de Desenvolvimento Sustentável da Região Turística (PDSRT) do Meio-norte (Brasil)
O turismo vem apresentando resultados positivos nos últimos anos e a atividade se consolidando no País como um importante vetor de desenvolvimento socioeconômico. Dados da OMT mostram que o turismo mundial cresceu 5\% em 2013, acima da expectativa de 3\% a 4\%, estima-se, ainda, que para o ano de 2022 o turismo seja responsável por gerar 3,63 milhões de empregos, estes relacionados à hotelaria, agências de viagens, companhias aéreas, outros tipos de transportes de passageiros, restaurante e lazer.

Desse modo, podemos observar a importância da atividade turística e seu contínuo processo de desenvolvimento, que se encontra não só ligado à atividade econômica, como também a um complexo fenômeno socioespacial. Dessa forma, o turismo vem acarretando transformações espaciais, adquirindo ao longo dos anos uma participação fundamental do poder público, no que diz respeito às políticas e planos de incentivos ao planejamento turístico. Assim, a região passa a ser um conceito que auxilia a elaboração de planos de desenvolvimento voltados para o turismo, mesmo que suas bases epistemológicas não sejam evidenciadas. Este fato ocorre na própria elaboração do PDSRT que não leva em consideração as complexidades da formação da Região Meio-Norte, e os conflitos existentes nessa região desde a era Colonial, como a zona de litígio entre o Ceará e o Piauí.

Perante tais afirmações, esta pesquisa tem como principal foco entender a utilização do conceito de região na estruturação de uma nova política pública criada através do Decreto federal s/n. de 6 de novembro de 2008, no qual dispõe sobre o Plano de Desenvolvimento Sustentável da Região Turística (PDSRT) do Meio-Norte. O PDSRT se versa de uma recente política de regionalização do turismo (2009) que tem como base o discurso do desenvolvimento sustentável através da integração turística de noventa municípios de três estados da região do Nordeste: Ceará, Piauí e Maranhão. Fruto da Política Nacional de Desenvolvimento Regional ${ }^{1}$ (PNDR) a partir do Ministério da Integração em parceria com o Ministério do Turismo ${ }^{2}$, o Plano apresenta como principal objetivo de promover de forma integrada o desenvolvimento sustentável dos municípios participantes, para a elevação da qualidade de vida da população (BRASIL, 2009).

Assim, faz-se necessário embasar a análise do conceito de região, visto os vários usos desse termo para justificar a delimitação espacial, como por exemplo, o seu uso para finalidade política. Na intenção de entender a utilização do termo "Meio-Norte", sobre a ótica da regionalização turística, foi preciso investigar as particularidades do planejamento regional do Brasil, em especial da região Nordeste.

As argumentações e questões a serem discutidas nessa pesquisa, além da Introdução e das Considerações Finais, foram divididas e estruturadas em três tópicos: o primeiro tópico intitulado como: O PDSRT e a sua localização Geográfica, que aborda a constituição do Plano Meio-Norte e a sua localização geográfica; o segundo tópico intitulado: O surgimento da região Meio-Norte, que tratará da discussão do surgimento do termo Meio-Norte na construção dos vários modelos regionais do Brasil. Esse procedimento auxiliará no entendimento sobre a inserção desta região no processo de regionalização das políticas públicas de turismo e como o conceito de região é utilizado para esses fins de planejamento. E o terceiro tópico: O conceito de região no plano Meio-Norte, o qual esclarecerá a relação desse conceito com o planejamento do Plano Meio-Norte. 


\section{O PDSRT e a sua localização geográfica}

O Plano de Desenvolvimento Sustentável da Região Turística (PDSRT) do Meio Norte, também sendo tratado nessa pesquisa de Plano Meio-Norte, abrange um total de noventa municípios localizados nos estados do Ceará, Piauí e Maranhão. Em sua primeira fase, quando foi lançado em documentos oficiais de 2009, o Plano era composto por setenta e sete municípios divididos em sete regiões estaduais de planejamento. Em 2010, em sua segunda fase, o Conselho Gestor, responsável pela implementação do Plano, atendendo ao pedido do Governo do Estado do Maranhão, incluiu mais treze municípios das microrregiões do Baixo Munim e Baixo Itapecuru, localizados nesse Estado, totalizando noventa municípios.

Na Figura 1 podemos observar a área de abragência do Plano compreendendo as regiões estaduais de planejamento do nordeste maranhense, norte piauiense e do noroeste cearense. De acodo com o Censo realizado pelo Instituto Brasilerio de Geografia e Estatística (IBGE) 2010, a área de abrangência do Plano Meio-Norte corresponde a 78 mil km2, ocupado por mais de 2 milhões de habitantes. Desse total de área, o estado do Maranhão, que corresponde a 35 municípios, apresenta a maior área coberta pelo plano, seguido pelo estado do Piauí com 33 municípios e Ceará com 22 municípios.

O processo de elaboração do plano baseou-se na metodologia do planejamento territorial participativo, sendo observadas três condições essenciais que vão desde o envolvimento de diversos órgãos setoriais, passando pela participação efetiva dos estados e municípios integrantes até a própria participação social.

Foram realizadas consultas públicas, que contaram com a participação de 2.250 pessoas, em seis "cidades-pólos" das regiões estaduais de planejamento: Barreirinhas (Lençóis Maranhenses) e Chapadinha (Alto Munim e Baixo Parnaíba) no Maranhão; Esperantina (Cocais) e Parnaíba (Planície Litorânea) no Piauí; Camocim (Litoral Oeste) e Tianguá (Ibiapaba) no Ceará. Também são apresentadas no Plano, várias ações de infraestrutura, que partem desde a implementação e paviemntação de vias que integram os estados integrantes até a construção e reforma de aeroportos e portos.

Vale salientar, que o Plano prioriza as ações de infraestrutura no turismo sol e praia, isto é, nos municípios litorâneos, principalmente para aqueles que fazem parte do roteiro da Rota das Emoções. O fato é que, além dos agenciamentos financeiros para a construção de vias de acesso e outras obras de mobilidade, os principais destinos turísticos (Jericoacoara, Delta do Parnaíba e Lençóis Maranhenses) estão situados em parques ambientais.

Essas estratégias colocam em contradição o próprio discurso sustentável do Plano, afinal, ao priorizar obras de acessibilidade entre esses pontos turísticos, acabam pondo em risco a própria zona costeira que é considerada um local de fragilidade ambiental.

Para além dessas questões, o que buscamos nesse artigo é fazer um resgate do uso do conceito de região, no que diz respeito à forma como esse termo é tratado no planejamento regional, em especial no Plano Meio-Norte. Levando-se em conta as polêmicas históricas da inserção dos estados do Maranhão e Piauí na região Nordeste, é de grande importância entender como seria possível essa "nova” divisão regional proposta pelo PDSRT ao referir-se a Região Meio-Norte composta pelos estados do Ceará, Piauí e Maranhão, na abrangência de noventa municípios. Para tratar esse assunto, far-se-á uma breve introdução sobre o surgimento da Região Meio-Norte perante as divisões regionais do País.

Geografia Ensino \& Pesquisa, v. 18, n.2, p. 25-38, maio/ago. 2013.

Araújo, L. L. B.

ISSN 2236-4994 I 27 
Figura 1 - Localização da área de abrangência do PDSRT do Meio-Norte..

3 Um fato importante que devemos lembrar é a disputa entre os estados do Ceará e Piauí desde a separação da capitania secundária do Ceará da capitania-geral do Maranhão e Grão-Pará. As disputas territoriais entre Ceará e Piauí são pela região da Ibiapaba. Há relatos de acordo de trocas de município entre os dois estados. Como o acordo político não foi bem definido a indefinição acerca da divisa entre os Estados persistem, criando a atual área de litígio. As discussões sobre a área de litígio entre os estados do Piauí e Ceará se fazem de suma importância perante a composição da região Meio-Norte dentro das perspectivas do PDSRT, o fato é que próprio plano não faz qualquer menção ao assunto referido.

Geografia Ensino \& Pesquisa, v. 18, n. 2 p. 25-38, maio/ago. 2014

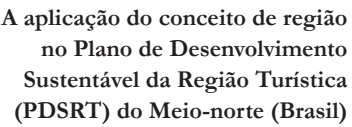

A aplicação do conceito de região no Plano de Desenvolvimento Sustentável da Região Turística (PDSRT) do Meio-norte (Brasil)

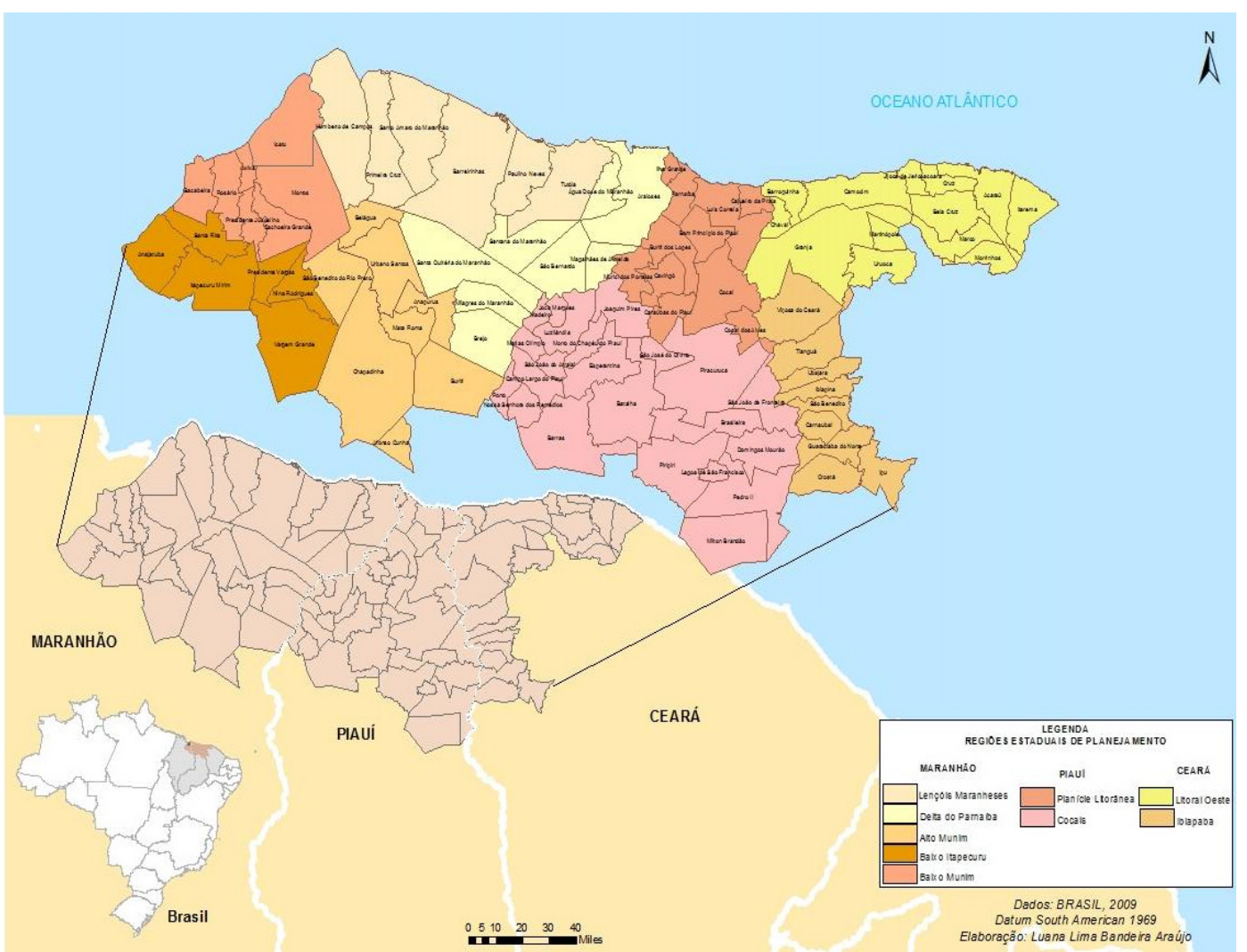

Fonte: elaborado pelos autores

\section{O surgimento da região Meio-norte}

Historicamente os estado do Maranhão e Piauí, por constituírem uma transição entre o Nordeste e a Amazônia, passaram a fazer parte, em alguns critérios de divisões regionais, da região Norte e, seguindo outros critérios, da região Nordeste. Em pleno século XXI ainda podemos apontar as peculiaridades em vincular os estados do Piauí e Maranhão dentro da macrorregião do Nordeste do Brasil.

Para chegarmos a uma resposta do surgimento do termo Meio-Norte na divisão regional brasileira é preciso voltar no tempo, mas precisamente em 1612, ano em que o Maranhão foi invadido pelos franceses, fundando a França Equinocial e sendo posteriormente expulsos pelos portugueses e espanhóis. Portugal em 1621, a fim de consolidar a ocupação desse território dividiu a colônia em dois estados: Estado do Maranhão e Grão-Pará, que só passaria a ser extinta em 1751, na administração do Marquês de Pombal. No lugar desses dois estados passa a existir o Estado do Grão-Pará e Maranhão com a capital em Belém.

Em 1772 foi extinto o Estado do Grão-Pará e Maranhão. De acordo com o ponto 3.2 denominado de Contexto Histórico do Plano Meio-Norte (p. 22) a Capitania do Grão Pará absorve a Capitania do Rio Negro (atual Amazonas) e a Capitania do Maranhão incluindo o atual Piauí ${ }^{3}$.

No decorrer do desenvolvimento histórico e geográfico do conceito de Região, várias foram as formulações metodológicas para a divisão territorial e regional brasileira. Um importante trabalho sobre o tema é feito pela geógrafa Angélica Alves Magnago (1995). A referida autora faz uma revisão de diferentes modelos da divisão regio- 
nal do País, tentando situá-los em relação à evolução do pensamento geográfico desde o início do século XX até o começo da década de 90. Magnago (1995) esclarece que a preocupação com o tema região sempre esteve presente nos estudos geográficos, tendo grandes contribuições teórico-metodológicas para a história do nosso país ${ }^{4}$.

Um fato importante a ser destacado é quando o termo Meio-Norte aparece dentro da composição da divisão regional brasileira. Os estados do Piauí e Maranhão são referidos, na divisão regional feita pelo engenheiro André Rebouças em 1889, como Zona da Parnaíba, composta por dez "zonas agrícolas". Segundo Guimarães (1941), o defeito dessa divisão regional consistiu no número excessivo de regiões. Este fato irá justificar, posteriormente, a divisão do país em "regiões naturais" feita por este geofísico na década de 1940, dividindo o Nordeste em Nordeste Ocidental (Maranhão e Piauí) e Nordeste Oriental. Por mais que os estados do Piauí e Maranhão tivessem suas diferenças, os mesmos eram postos na região Nordeste exatamente para não se estabelecer um número excessivo de regiões.

A acepção de região voltada ao natural/ambientalista de base naturalista norteou a construção de alguns conceitos importantes na Geografia, especialmente os climáticos, que determinavam o comportamento do homem, fazendo assim surgir o determinismo ambiental. Um marco na geografia regional brasileira, influenciada pelo determinismo geográfico, foi a obra de Delgado de Carvalho, em 1913, com a introdução do conceito de região natural. Mesmo sendo influenciado pelo possibilismo francês, o autor em sua proposta de divisão regional baseava-se no determinismo ambiental, levando em conta os elementos do meio-físico.

Na década de 1930, com o Estado Novo, o conhecimento das informações estatísticas tornou-se uma das prioridades nacionais. Perante essa necessidade surge o Conselho Nacional de Estatística e o Conselho Nacional de Geografia que estavam diretamente ligados ao Instituto Brasileiro de Geografia e Estatística (IBGE). Em 1938, nascido principalmente pela necessidade de elaboração de um anuário Estatístico Brasileiro, esse instituto realizou uma nova divisão regional do país, através da divisão regional, em uso no Ministério da Agricultura. Nessa nova proposta os estados do Piauí e Maranhão fazem parte da região Norte juntamente com os estados do Acre, Amazonas e Pará.

Em 1942, é realizada pelo IBGE, uma única divisão regional para o País. Essa divisão voltada principalmente para fins estatísticos, realizada pelo engenheiro Fábio de Macedo Soares Guimarães, foi executada de acordo com as coordenadas geográficas de Delgado de Carvalho. Nessa nova divisão o Brasil foi dividido em cinco grandes regiões, as "regiões naturais" - como ficaram conhecidas, que foram divididas com base nas condições naturais do território, ou seja, as condições físicas (clima, vegetação e relevo).

Nessa divisão regional a região Nordeste foi subdividida em Nordeste Ocidental, formada pelos estados do Maranhão e Piauí, e Nordeste Oriental, composto pelos estados do Ceará, Rio Grande do Norte, Pernambuco, Paraíba, Alagoas e o Território de Fernando de Noronha. Pode-se assim observar que os três estados que atualmente compõem o PDSRT - Ceará, Piauí e Maranhão estão fragmentados nessa época.

Fábio Guimarães (1942) retoma as discussões da inclusão do Piauí e Maranhão alertando para o fato desses estados serem inclusos na região Nordeste por conta dos fatores geológicos, climáticos e botânicos. Segundo o autor:

[...] É certo que os dois Estados separados pelo Parnaíba constituem realmente a transição entre o Nordeste semi-árido e a Amazônia super-úmida [...] Pelas condições geológicas, climáticas e botânicas, o oeste maranhense é tipicamente amazônico e o sudeste piauiense é francamente nordestino;
${ }^{4}$ Assim como Magnago (1995) vários foram os geógrafos que contribuíram para o estudo da geografia regional brasileira, dentre eles podemos citar: Vianna (1984) sobre a Divisão Territorial do Brasil, Zarur (1946) com seu trabalho sobre Análises Regionais como também clássicos como Guimarães (1942) em seu trabalho sobre a Divisão Regional do Brasil dentre outros.

Geografia Ensino \& Pesquisa, v. 18 n.2, p. 25-38, maio/ago. 2013.

Araújo, L. L. B.

ISSN 2236-4994 
${ }^{5}$ É valido lembrar os fatores históricos que existe nessa região principalmente no período colonial. Ainda de acordo com Andrade (1973) essa região era dividida entre o estado do Piauí, com uma economia voltada para a pecuária, e estado do Maranhão agropecuarista (principalmente para o cultivo do arroz).
Geografia Ensino \& Pesquisa, v. 18, n.2 p. 25-38, maio/ago. 2014

A aplicação do conceito de região no Plano de Desenvolvimento Sustentável da Região Turística (PDSRT) do Meio-norte (Brasil) a maior parte dos dois estados difere de uma e outra região, por condições próprias e é a flora, com seus "cocais" de babaçu, que dá a nota característica a essa parte. Desde que, numa divisão prática não podemos pensar em desmembrar unidades políticas, e sendo também inconveniente cairmos na sub-divisão excessiva, num grande número de regiões, somos forçados a incluir tais Estados na região vizinha à qual mais se assemelham. O Maranhão e o Piauí diferem das regiões vizinhas, mas diferem muito menos do Nordeste do que na Amazônia (Idem, 1942, p.37).

Manuel Correia de Andrade (1973, p. 21) em sua obra "A terra e o bomem no nordeste" também aborda sobre a dificuldade dos estudiosos em delimitar a região nordestina, assim como da região Meio-Norte este destaca:

[...] Se analisarmos as tentativas até agora feitas no sentido de dividir o país em regiões naturais, observaremos que, se alguns autores concordam em colocar no Nordeste apenas os Estados do Ceará, Rio Grande do Norte, Parnaíba, Pernambuco e Alagoas, outros entendem a região para o Nordeste, incluindo na mesma o Piauí e o Maranhão, enquanto outros, ainda, estendem-na para o Sul, incluindo em seus limites Sergipe e parte da Bahia, geralmente até a altura do Recôncavo [...].

Ainda perante as indagações de Andrade (1973) notamos o aparecimento da região do Meio-Norte na composição da paisagem do Nordeste através do clima, do regime pluvial e da vegetação. Neste caso a região Meio-Norte ainda é extrativista e pecuarista na qual o autor define:

O Meio Norte compreende extensa área do Piauí e do Maranhão onde dominam os cerrados, nas chapadas e interflúvios, e a floresta de cocais nas baixadas e nas várzeas. Ela se estende por cerca de $422.911 \mathrm{~km} 2$ e é drenada por rios caudolosos permanentes como o Parnaíba, o Itapecururu, o Mearim e seus dois grandes afluentes: o Grajaú e o Pindaré. Aí dominam as formas terciárias e, consequentemente, solos arenosos, muito permeáveis [‥] (p.53).

Para o autor, os fatores físicos da região o levam a considerar o Meio Norte como uma área de transição entre o Nordeste, o Norte e o Centro-Oeste do país. Este também define a chamada Guiana Maranhense como uma porção amazônica que tem o avanço do povoamento muito semelhante ao do Meio Norte, ao qual se encontra intimamente ligado, pois sua ocupação se fez em molde maranhense ${ }^{5}$. Assim como Guimarães, Andrade também recorre ao babaçual como principal marca do Meio-Norte.

Ainda na década de 1940, apesar da divisão regional manter as cinco grandes divisões regionais, segundo Araújo (2009), essa divisão passou a adotar critérios, seguindo a metodologia e os aspectos das características homogêneas do meio físico, sendo originadas 30 regiões, 79 sub-regiões e 229 pequenas áreas chamadas de zonas fisiográficas. De acordo com Matos (2013, p. 95):

[...] a base teórico-metodológica de elaboração dessas zonas passa a influenciar o modo de constituição do pensamento regional. Fruto dessa configuração, temos a tomada do processo de reformulação das divisões regionais a partir da segunda metade da década de 1960, tendo como um primeiro resultado a substituição do termo zona fisiográfica para microrregião homogênea. 
Nas décadas de 1950 e 1960 os conceitos de região e de planejamento regional ganharam mais atenção. Este fato ocorre por conta da maior atenção dada pelo governo brasileiro - época em que foi feita a implantação do Estado militarista - ao discurso da política de correção da desigualdade do território brasileiro, através da ideologia desenvolvimentista. Para Oliveira (1987) o planejamento no Brasil só veio contribuir para o projeto integracionista, criando "pólos de desenvolvimento" a fim de corrigir as consideradas "disparidades regionais".

Segundo Rocha \& Conceição (2009), o planejamento emerge como uma forma de intervenção do Estado sobre as contradições entre a reprodução do capital em escala nacional e regional, que tomam a aparência de conflitos inter-regionais. Os geógrafos vinculados ao IBGE passaram a produzir importantes trabalhos sobre urbanização, relacionando-os ao processo de industrialização. Relacionado às ideias de desenvolvimento, o planejamento territorial também teve grande ampliação.

Ainda na década de 1950, mas precisamente em 1957, segundo Matos (2013, p.115) "é editado o primeiro grande trabalho a tratar da relação entre Piauí e Maranhão na esfera federativa". Esse documento, organizado pelo IBGE faz parte da coletânea intitulada "Enciclopédia dos municípios brasileiros". Logo em seu prefácio, o documento se refere a dificuldade em apresentar a região Meio Norte, devido às deficiências de estudos relacionados aos "dois estados mais pobres da Federação" (IBGE, 1957, p.3).

Na divisão regional em vigor na época, a de Fábio Guimarães em 1942, já indicava a separação dos estados Maranhão e Piauí da região Nordeste, sob a denominação de Nordeste Ocidental. Sobre essas premissas a publicação do IBGE traz a tona as descrições naturais da região daí "a tendência e a justificação para o reconhecimento de uma área geográfica intermédia, à guisa de transição entre o Nordeste, a Amazônia e o Brasil Central" (IBGE, 1957, p. 22). Isto é, o Meio-Norte é comparado a uma área de caráter intermediário e transicional, distinguindo-se do Nordeste por ser "uma passagem para a Amazônia e o Centro-Oeste enquanto o Nordeste Oriental, que é o tradicional, apresenta-se bem definido, principalmente quanto ao clima" (Idem, p.22).

A divisão em regiões naturais do Meio Norte é constituída a partir de três tipos: planície, "cuestas" e chapadões, o que reafirma a situação naturalista dessa região, nas quais o IBGE alega ainda a dificuldade em traçar os limites entre esses domínios:

\begin{abstract}
Traçar o limite entre a planície e as outras zonas é relativamente fácil, mas, fazer o mesmo entre "cuestas" e os chapadões ocasiona sérias dificuldades, por surgirem vários problemas de difícil solução. Verifica-se igual embaraço no contato da região Amazônica com o Meio-Norte: forma-se uma longa faixa de transição, de localização imprecisa, apresentando a vegetação características amazônicas, embora haja outros aspectos que se assemelham aos da planície do Meio Norte. Somente um logo e acurado estudo poderá indicar com precisão os limites dessa área (IBGE, 1957, p. 32).
\end{abstract}

Dessa forma, segundo Matos (2013), era notória a preocupação do IBGE em formar um banco de ilustrações sobre o Maranhão e o Piaú a fim de descrever as peculiaridades desses territórios. Ainda segundo o autor:

[...] Cercado por figuras que buscava cobrir as mais diversas perspectivas dos territórios do Piauí e Maranhão, este trabalho possibilitou o delineamento imagético do país em torno daquela espacialidade. Evitando estabelecer um maior debate sobre a situação retratada nas imagens apresentadas,
Geografia Ensino \& Pesquisa, v. 18, n.2, p. 25-38, maio/ago. 2013 .

Araújo, L. L. B.

ISSN 2236-4994 
o documento serviu como uma espécie de relicário ilustrativo e descritivo dos aspectos ditos como naturais dessa construção regional (Idem, p. 115).

Na década de $1960^{6}$, época da Geografia quantitativa, a vinculação da geografia e da estatística, segundo Perides (1994), surgiu no âmbito dos estudos da regionalização como intuito de elaborar uma divisão regional para o país centrada em processos de polarização de áreas em torno de atividades urbano-industriais ${ }^{7}$.

Ainda segundo Perides (1994), as novas propostas de regionalização teriam ganhado um caráter utilitarista, onde a divisão do espaço seria uma aplicação prática com alguma finalidade específica. Com base na "Geografia Quantitativa", fortemente utilitarista e a serviço do planejamento, foi fornecida a base metodológica da nova divisão regional do Brasil, que se unia ao propósito de estabelecer uma nova divisão regional capaz de suprir as necessidades de expansão e de reprodução do capitalismo em sua fase monopolista. Segundo o IBGE (2010, p. 18):

${ }^{6}$ Cabe ressaltar que, em 1967, foi lançado pelo IBGE, a obra intitulada Panorama Regional do Brasil (IBGE, 1967), sendo organizada em cinco capítulos, um para cada região. O objetivo principal da obra foi caracterizar as regionais do Brasil apontando os contrates e desigualdades das mesmas.

Marília Velloso Galvão (1969); Orlando Valverde (1967); Pedro Pinchas Geiger (1967a, 1967b, 1967c, 1970), e Speridião Faissol (1973), são exemplos de artigos publicados na Revista Brasileira de Geografia, que reproduzem diversos aspectos teórico-metodológicos contidos na Divisão Regional Brasileira de 1970.

Geografia Ensino \& Pesquisa, v. 18, n.2 p. 25-38, maio/ago. 2014

A aplicação do conceito de região no Plano de Desenvolvimento Sustentável da Região Turística (PDSRT) do Meio-norte (Brasil)
Essa regionalização perdurou até 1968 , quando foi feita nova proposta de divisão regional denominada Microrregiões Homogêneas, definidas a partir da organização do espaço produtivo e das teorias de localização dos polos de desenvolvimento, identificando a estrutura urbano-industrial enquanto elemento estruturante do espaço regional brasileiro.

Ainda na década de 1960, Pedro Pinchas Geiger revela uma nova constituição para a divisão regional brasileira. O geógrafo brasileiro leva em consideração o processo histórico da formação do espaço do País, associando a industrialização aos aspectos naturais, passando a dividir o Brasil em três complexos naturais: Nordeste, Centro-Sul e Amazonas. Essa divisão foi alvo de várias críticas por não respeitar os limites estaduais, uma vez que as estatísticas socioeconômicas eram produzidas pelo Estado.

Geiger (1967) elabora uma nova divisão do IBGE intitulada Divisão Geoeconômica, onde apresenta a estruturação de quatro sub-regiões: Zona da Mata; Agreste; Sertão (dando destaque ao polígono da seca) e o Meio-norte, (composto pelo estado do Maranhão e parte do Piauí). A compreensão da formação do termo Meio-Norte se apresenta novamente como uma zona de transição marcada pelo domínio morfoclimático da Mata dos Cocais. Segundo Matos (2013, p.122) "Meio-norte, Sertão, Agreste e Zona da Mata, apesar de não oficializarem-se na configuração regional brasileira, passam a contribuir para a estabilização do Nordeste no cenário nacional."

Ainda na década de 1960, Lima (2002) enfatiza que a expansão do capitalismo no Pós-Segunda Guerra Mundial, trouxe uma necessidade de reformular a divisão regional brasileira devido às transformações socioeconômicas, fazendo surgir novas formas de organização do espaço brasileiro. Em 8 de maio de 1969 surge uma nova divisão regional que permanece até hoje, na qual identifica cinco Grandes Regiões que segundo Magnago (1995) foram criadas para fins didáticos enquanto as microrregiões homogêneas utilizadas para fins estatísticos. Nessa divisão os Estados do Ceará, Piauí e Maranhão voltam a compor a macrorregião do Nordeste.

Em decorrência dessas novas pesquisas, o IBGE publica em 1972 as Regiões Funcionais Urbanas, essa divisão objetivava subsidiar as políticas de descentralização que estivessem voltadas para o desenvolvimento local, regional e nacional. Em 1976 o IBGE definiu 87 mesorregiões homogêneas, a partir da agregação das microrregiões 
que foram realizadas, havendo "a necessidade de se ter um nível de agregação espacial intermediário entre as Grandes Regiões e as Microrregiões Homogêneas, foram definidas as Mesorregiões por agrupamento de Microrregiões" (IBGE, 2010, p.18).

Já na década de 1980, surge como um novo aporte teórico, o Materialismo Histórico, dando destaque à expansão do capitalismo e às diferenciações espaciais. Ainda segundo a autora, anteriormente referida, a metodologia defendida nesses estudos apoiava-se na noção de totalidade nacional, tomando as Unidades de Federação como um universo de análise, criando-se as mesorregiões e microrregiões, passando a se denominar de geográficas.

Podemos perceber que foram várias as mudanças teórico-metodológicas acerca da temática regional brasileira. As propostas de divisão regional do Brasil perderam sentido por conta da evolução das dinâmicas urbanas, da própria industrialização e da atual globalização. As desigualdades regionais surgem nessa perspectiva, tornando-se cada vez mais difícil uma compreensão do território nacional a fim de reduzir tais desigualdades regionais.

A região Meio-Norte, relacionada à divisão regional brasileira, é posta na existência de uma sub-região definida como uma faixa de transição, ou seja, leva em consideração os aspectos naturais usados como critérios para regionalizar o espaço do Nordeste. Aproveitando-se das belezas naturais desses estados e alegando o turismo como uma atividade solucionadora de graves problemas de ordem socioeconômica, o Plano Meio-Norte vem definir os noventa municípios que o compõe em uma região turística. Esses fatos nos trazem à tona o rompimento das barreiras tradicionais políticas na divisão regional do Brasil, passando a funcionar como base da organização regional do turismo. O PDSRT vem a romper essas barreiras a fim de formar outra região sobre a égide da dinâmica turística. Desse modo, o conceito de região acaba sendo empregado largamente sem ter seu devido tratamento epistemológico, é o que iremos melhor esboçar no próximo tópico.

\section{O conceito de região no plano Meio-norte}

No decorrer dos séculos, várias foram as abordagens do termo Região. Primeiramente nos voltemos ao termo Região que no senso comum, no nosso cotidiano, este/ esta é tratado como uma forma de referência de diferentes lugares, ou mesmo de uma divisão regional, sendo reconhecido na perspectiva de unidade administrativa. Por se tratar de um termo polissêmico, assim como todos os outros conceitos chave da geografia, o que marca a trajetória do conceito de região, como explica Heidrich (1999, p.63) é a relação aos aspectos da "totalidade/unidade, fragmentação/segmentação, integração, etc., do espaço, fatos que tem a ver com o conhecimento de territórios"

Mesmo que muitas ciências evoquem a região para localizar fenômenos ou para objeto de estudo, Lencioni (2003) nos chama atenção ao fato de que na Geografia é que se encontram as bases do desenvolvimento de conceitos e noções relativas a esse termo. Ainda nessa perspectiva, Gomes (2008), enfatiza que o uso do termo região é um pouco mais complexo, pois ao tentarmos fazer dela/dele um conceito científico, acabamos herdando as indefinições, a força de seu uso na linguagem comum e a isto se somam as discussões epistemológicas que o emprego deste conceito nos impõe.

A imagem da região Nordeste sempre esteve ligada as suas condições inóspitas geomorfo-climáticas, fazendo desta um aspecto que não favoreceu, por muito tempo,
8 Outro autor que também enfatiza tal perspectiva é Haesbaert (2010). Este ressalta que a região está ligada à "relação parte/todo", à direção e localização, como nas definições "esfera de domínio de algo" ou "espaço ocupado por alguma coisa" (Idem, p.22).

Geografia Ensino \& Pesquisa, v. 18, n.2, p. 25-38, maio/ago. 2013.

Araújo, L. L. B.

ISSN 2236-4994

I 33 
seu desenvolvimento econômico e social. Este fato fez com que a imagem da seca e da fome ficassem ligadas negativamente a essa região, surgindo uma visão focada na ideia de pobreza, impedindo a apreensão dos desdobramentos a favor de seu desenvolvimento econômico. Este imaginário, como demonstra Dantas (2009), surge quando a seca se torna uma referência aos problemas socioeconômicos (a fome, a miséria, o subdesenvolvimento). De acordo com Castro (1992, p. 59):

A imagem projetada da região era a caatinga ressequida, a indefectível carcaça de um boi e os retirantes, magros, com seus poucos pertences entrouxados e equilibrados sobre a cabeça. [...] Afinal, trata-se de um pedaço do país pouco aquinhoado pela natureza. A culpa da miséria era dos céus e não dos homens. A estes cabiam tentar minorar os seus efeitos com recursos técnicos e financeiros que, naturalmente, deveriam vir de onde eles existissem. [...] Os problemas sociais aí eram ofuscados pela questão maior da seca e pela necessidade de preservar uma atividade econômica regional.

Essa observação já tratada por Dantas (2009), afirma que até os anos 1970, os investimentos na área do turismo no Brasil eram pouco explorados, com exceção de alguns estados, como o Rio de Janeiro. No final do século XX, este fenômeno surge como uma força social, cultural, política e econômica capaz de movimentar milhões de pessoas e bilhões de reais em todo o país.

\begin{abstract}
A indicação da imagem positiva do nordeste do Brasil a partir do final dos anos 1980, associada à possibilidade de exploração turística das paisagens litorâneas tropicais, induz políticas de desenvolvimento econômico cujos desdobramentos se dão, grosso modo, na estruturação das metrópoles nordestinas [...] (DANTAS, 2010, p. 09).
\end{abstract}

Por ser utilizado em diversas áreas, o conceito de região acaba sendo empregado largamente sem ter seu devido tratamento epistemológico. Pode-se identificar isso nos termos que servem para designar elementos do turismo, como por exemplo, o "Turismo Regional" ou "Região Turística". A região utilizada no PDSRT como "região turística do Meio-Norte" também se encontra vinculada a esse campo genérico, além disso, passa a ser um exemplo das várias proposta de planos regionais de desenvolvimento do país. Por conta do fracasso de vários planos regionais elaborados pelo Estado houve o descrédito do próprio conceito de região. Segundo Breitbach (1988) a necessidade de utilizar o termo região passa a designar, antes de tudo, uma área territorial escolhida sob um critério subjetivo conforme a necessidade do pesquisador naquele momento. Ainda de acordo com o autor:

Geografia Ensino \& Pesquisa, v. 18 n. 2 p. $25-38$, maio/ago. 2014

\footnotetext{
A aplicação do conceito de região no Plano de Desenvolvimento Sustentável da Região Turística (PDSRT) do Meio-norte (Brasil)
}

As conseqüências da utilização indiscriminada e subjetiva do conceito de região se fazem sentir, com muito a ênfase, principalmente quando se trata de planejamento regional. Freqüentemente, o conceito de região, subjacentes a planos e programas normalmente disponíveis, não ultrapassam e muito as abordagens geográficas e administrativas no sentido escrito, quer dizer, a delimitação meramente territorial do espaço. Ora, tal noção não contempla a realidade regional em seu conjunto, nem a relação dessa com o espaço, prejudicando a percepção da realidade e comprometendo a qualidade dos diagnósticos a partir daí elaborados. Os planejadores deparam-se, então, com as necessidades de "controlar" as desigualdades regionais num contexto capitalista, o qual, devido a sua própria natureza, as produz e reproduz sistematicamente, como condição essencial de sua sobrevivência [...] (BREITBACH, 1988, p. 19). 
pelo Governo desde a implantação do PRODETUR/NE, principalmente quanto à regionalização litorânea. Uma dessas propostas de planejamento a nível regional é o próprio PDRST, que faz do turismo um potencializador de riquezas para a região, que é destacada pelo plano por possuir baixíssimos Índices de Desenvolvimento Humano no país.

É importante salientar que o turismo antes de ser uma atividade econômica é um fenômeno social. Segundo Coriolano (2006, p.368) “o turismo enquanto prática social é também econômica, política, cultural e educativa, envolvendo relações sociais e de poder entre residentes e turistas, produtores e consumidores". Os estudos que levam o turismo como eixo principal de pesquisa revelam que este vem deixando de ser visto apenas como uma atividade econômica, mas se tornando multidisciplinar. Para que essa atividade seja posta em prática este setor acaba se apropriando do espaço e transformando-o, com essa apropriação o turismo acaba produzindo novas configurações sócio-espaciais. Tanto o planejamento turístico quanto as políticas públicas de turismo são postas em ação. Colocadas em prática adequadamente, tornam-se uma ferramenta eficaz de dinamização do espaço turístico, o que faz gerar novas propostas de planejamento regional. O que pode ser observado nas propostas de planejamento regional discutidas até então, é o discurso do desenvolvimento regionalista, disposto a resolver as fragilidades tanto sociais quanto econômicas das diferentes macrorregiões brasileiras.

Dessa forma, a região passa a se tornar uma ferramenta de interesse na elaboração de planos estratégicos voltados para o turismo, não podendo tratar de forma separada a formação da região Meio-Norte no contexto das práticas da divisão regional brasileira. Assim, a região no PDSRT é utilizada como estratégia para afirmar a construção de uma região em prol do estabelecimento de uma vocação turística em torno dos estados que o compõe.

\section{Considerações Finais}

O PDSRT vem buscar a homogeneidade da região a fim de promover uma pseudo-integração turística entre os municípios que o compõe. Esse fato pode ser esboçado no próprio processo de formação Macro-Regional brasileiro, levando-se em conta a formação do termo Meio-Norte, devido à complexidade de incluir os estados do Piauí e Maranhão na macrorregião do país.

Como se pode perceber, ao longo do processo histórico-geográfico da região, vários são os questionamentos que envolvem o PDSRT, entre eles os próprios fatores climáticos, as questões sociais e culturais que passam a ser ignoradas na construção dessa sub-região nordestina além da própria mudança de governo dentro dos estados; da distância entre os municípios envolvidos; da não inclusão das capitais de cada estado participante, sendo estas as principais portas de entrada de investimento para os estados.

A própria idealização da regionalização do PDSRT parte da justificativa de existir uma potencialidade turística nessa região. Observando a proposta regional, percebe-se que o discurso visa à abrangência de políticas de infraestrutura generalizantes, elaboradas para a efetivação da atividade turística, sobretudo nos três núcleos principais - Lençóis, Delta e Jericoacoara - sobre o qual se projeta a expansão do referido

Geografia Ensino \& Pesquisa, v. 18, n.2, p. 25-38, maio/ago. 2013.

Araújo, L. L. B.

ISSN 2236-4994 
"desenvolvimento sustentável”, apresentado no título do referido plano.

Esse planejamento estratégico acaba sendo contraditório. Ao trazer o turismo sob a ótica de atividade econômica, o referido plano abrange de forma secundária a dinâmica social local, contrariando a lógica desenvolvimentista proposta. Além disso, o destaque dado à zona costeira como principal estratégia para a implementação de infraestrutura acaba colocando em risco essa área ambiental.

Desse forma, através das particularidades do planejamento regional do Brasil, em especial da região Nordeste foi possível perceber como conceito de região continua sendo utilizado em vários projetos de planejamento estatal do país, sem ter o seu devido tratamento epistemológico. Ao analisar o PDSRT do Meio-Norte, possibilita-se observar a repetição dos ranços que perpassam a história regional brasileira, marcada por divisões que longe de propor a formação de redes de confluências, terminam por justificar alguma política reducionista.

Enfatiza-se que o PDSRT do Meio-Norte apresenta expressiva fragilidade como instrumento de desenvolvimento do turismo configurando-se até o momento como incapaz de promover projetos estruturantes de caráter econômico-social, envolvendo efetivamente uma cadeia de atores e atividades interligadas. Visto que várias discussões que envolvem os três estados não são debatidas na construção do PDSRT, como a própria complexidade da constituição da Região "Meio-Norte" no contexto regional brasileiro.

Nota-se numa vertente a criação de um discurso simbólico, entoando a unidade desses três polos turísticos - unidade essa assentada pela ótica ambiental, histórica e cultural - ao mesmo momento que numa segunda vertente é proposto a estruturação de vias de interligação entre essas três localidades, até então inexistentes. Surge nesse contexto o termo vocacional para o turismo, a fim de justificar a proposição dessa política de regionalização e ocultar a falta de projeto específico sobre as intencionalidades com a elaboração do referido plano.

\section{Referências}

ANDRADE, M. C. de. A terra e o homem no Nordeste. 3. ed. rev. e atual. São Paulo: Brasiliense, 1973. $251 \mathrm{p}$.

ARAÚJO, M. M. S.. A Cidade de Alagoinhas na Dinâmica da Espacialidade Funcional Urbana da Região Litoral Norte da Bahia. 190f. Dissertação (Mestrado em Geografia) - Universidade Federal da Bahia, UFBA, 2009.

BRASIL. Ministério da Integração Nacional. Plano de Desenvolvimento Sustentável da Região Turística do Meio-Norte. Brasília: MIN, 2009.

Geografia Ensino \& Pesquisa, v. 18, n. 2 p. 25-38, maio/ago. 2014

A aplicação do conceito de região no Plano de Desenvolvimento Sustentável da Região Turística (PDSRT) do Meio-norte (Brasil)
BRASIL. Ministério do Turismo. Plano Nacional do Turismo: Uma viagem de inclusão 2007-2010 / Ministério do Turismo. Brasília, 2007.

BREITBACH, Á C de M. Estudo sobre o conceito de região. Porto Alegre: Fundação de Economia e Estatística Siegfried Emanuel Heuser, 1988. 
CASTRO, I. E. de. O mito da necessidade: discurso e prática do regionalismo nordestino . Rio de Janeiro: Bertrand Brasil, 1992.

CORIOLANO, L. N. M. T. Turismo: prática social de apropriação e de dominação de territórios. In: (Org.) Lemos et al. América latina: cidade, campo e turismo. São Paulo: Clacso, 2006.

DANTAS, E .W. C. et al. Turismo e Imobiliário nas metrópoles. Rio de Janeiro: Letra Capital, 2010.

DANTAS, E. W. C. Maritimidade nos trópicos: por uma geografia do litoral. Fortaleza: Edições UFC, 2009.

GEIGER, P. P. Geografia e planejamento. Revista Brasileira de Geografia. v.29, n.3, 1967, p.111118.

GOMES, P. C. da C. Geografia: conceitos e temas. 11.ed. Rio de Janeiro:Bertrand Brasil, 2008.

GUIMARÃES, F. de M. S. Divisão regional do Brasil. Rio de Janeiro: IBGE, 1942.

GUIMARÃES, F. de M. S.. Divisão regional do Brasil. Revista Brasileira de Geografia, Rio de Janeiro, $\mathrm{n}^{\mathrm{o}} 2$, ano III, abril/junho 1941. Reeditada em 1988, v. 50, n. especial, t. 1, pp. 9-66.

HAESBAERT, R. Regional-global: dilemas da Região e da Regionalização na Geografia Contemporânea. Rio de Janeiro: Bertrand Brasil, 2010.

HEIDRICH, A. L. Região e Regionalismo: observações acerca dos vínculos entre a sociedade e o território em escala regional. Boletim Gaúcho de Geografia, Porto Alegre, v. 25, p. 63-76, 1999.

IBGE. Censo 2010. 2010. Disponível em: http://www.censo2010.ibge.gov.br. Acessado em 20 de Fevereiro de 2012.

IBGE. Geografia do Brasil: grandes regiões Meio-Norte e Nordeste. Rio de Janeiro: IBGE, 1962. (Biblioteca Geográfica Brasileira, série A, v. 3, n. 17).

IBGE. Enciclopédia dos Municípios Brasileiros. Volume III. Rio de Janeiro: IBGE, 1957.

LENCIONI, S. Região e geografia. São Paulo: Edusp, 2003.

LIMA, M. H. P. (org.). Divisão territorial brasileira. Rio de Janeiro: IBGE, 2002.

MAGNAGO, Angélica Alves. A divisão regional brasileira: uma revisão bibliográfica. Revista Brasileira de Geografia, Rio de Janeiro, v.57, n 4, p. 65-92, outubro-dezembro 1995.

MATOS, F. DE O. Formação e Limitações Regionais do Plano de Desenvolvimento Sustentável da Região Turística do Meio-Norte (Brasil). 2013. 249f. Tese (Doutorado em Geografia)- Universidade Federal do Ceará,UFC, 2013.

PERIDES, P. P. A divisão regional do Brasil de 1968: propostas e problemas. In: Revista do Departamento de Geografia, São Paulo, n.7, p. 87-94, 1994

ROCHA, R. R.; CONCEICAO, A. L. O planejamento regional: integrar para desintegrar. Scientia Plena, v. 5, p. 015401, 2009

OLIVEIRA, Francisco. A economia brasileira: crítica à razão dualista. 5ª ed. Petrópolis: Vozes, 1987.

Geografia Ensino \& Pesquisa, v. 18, n.2, p. 25-38, maio/ago. 2013.

Araújo, L. L. B. 


\section{Correspondência:}

\section{Luana Lima Bandeira Araújo}

E-mail: luana_b3@hotmail.com

Recebido em 25 de junho de 2013.

Aceito para publicação em 13 de agosto de 2014. 